\title{
Role balance and team development: A study of team role characteristics underlying high and low performing teams
}

\author{
Eric Chong \\ Victoria University of Wellington
}

\begin{abstract}
It has been suggested that the performance of a team is determined by the team members' roles. An analysis of the performance of 342 individuals organised into 33 teams indicates that team roles characterised by creativity, co-ordination and cooperation are positively correlated with team performance. Members of developed teams exhibit certain performance enhancing characteristics and behaviours. Amongst the more developed teams there is a positive relationship between Specialist Role characteristics and team performance. While the characteristics associated with the Coordinator Role are also positively correlated with performance, these can impede the performance of less developed teams.
\end{abstract}

\section{Introduction}

Teams combine the efforts of individual contributors and provide synergistic outcomes. This unique process, although not fully understood (Kozlowski and Klein, 2000), has led organisations to rely more and more on teams as prime movers for innovation and change. Fleming and Koppleman, 1997 cite large organisations in the USA such as Boeing, Chrysler, Corning, DuPont, Eastman Kodak, General Motors, Hewlett-Packard and Xerox as examples where teamwork is fully supported and encouraged. These leading organisations provide impetus for other organisations to follow and result in the study of high performing work teams being of ongoing interest (West \& Markiewicz, 2004). This paper explores the relationship between the individual roles in a team and the resulting team performance. In doing this, it aims to contribute to the understanding of how teams perform in a dynamic environment where they evolve through the different stages of team development.

\section{Team Roles and Team Performance}

Benne and Sheats (1948) studied small discussion groups that were engaged in problem-solving activities. They observed the emergence of Task and Maintenance roles of group members. The 'task roles' were identified by behaviours such as facilitating and co-ordinating group activities and suggesting new ideas and ways of solving problems. The 'maintenance roles' were related to behaviours that 'encouraged' group members such as praising, agreeing and accepting the contribution of others within the group. Bales (1950) built on the research into team roles by analysing the interaction between members of small groups and categorising the types of behaviour into task-oriented and socio-emotional. These early studies centred on the individual's behaviours within a group and the classification of these behaviours into broader roles. 
The interest in teams gained momentum in the 1980s with the publication of Belbin's (1981) work on successful teams. The research into teams and teamwork followed two lines of inquiry. Writers such as Belbin (1981, 1993), Woodcock (1989), Margerison and McCann (1990), Davis et al. (1992), Parker (1990) and Spencer and Pruss (1992) focused on team roles and how these affected team performance. These studies suggested that team performance was a function of the number and type of roles team members played. The number of roles for optimal performance varied from 15 (Davis et al., 1992) to four (Parker, 1990). This variation has been attributed to how roles were defined. Lindgren (1997) believed that, in a social psychological sense, 'roles' were behaviours one exhibited within the constraints assigned by the outside world to one's occupational position e.g. leader, manager, supervisor, worker etc. Personality traits, on the other hand, were internally driven and relatively stable over time and across situations. These traits affected behavioural patterns in predictable ways (Pervin, 1989) and, in varying degrees, become part of 'role' definition as well.

The other line of inquiry focused on measuring the 'effectiveness' of teams. Writers such as Deihl and Stroebe (1987), Gersik (1988), Evenden and Anderson (1992), Furnham et al. (1993), Cohen and Ledford (1994) and Katzenbach (1998) were concerned with high performing teams and the objective measurement of their effectiveness. McFadzean (2002) believed that the appearance of a number of models of team effectiveness was indicative of a variety of variables such as personality, group size, work norms, status relationships, group structure etc. that can impact on team 'effectiveness' and its measurement.

\section{Belbin's Team Roles}

Belbin's (1981) seminal work identified eight team roles, which were redefined and increased to nine roles in Belbin (1993), that emerged 'naturally' and had to be spread or 'balanced' amongst team members for the team to be high performing. He defined team performance in his earlier research in terms of the financial results the team achieved in a management simulation. Belbin believed that a management team of six persons was ideal for working on complex problems. This meant that each team member would have to take on more than one of the nine role characteristics listed in Table 1.

The Self Perception Inventory (SPI) used in Belbin's research consisted of seven sections. Each section had a heading and ten statements (see Appendix A). Respondents had ten points for each section to distribute amongst the statements. They were required to allocate more points for statements that they felt more accurately reflected their character and less points or zero to those that were less reflective of their character or totally irrelevant. Researchers have made comparisons of other established theoretical models with Belbin's original SPI and the Belbin Team Role Self-Perception Inventory (BTRSPI) developed in 1993. These comparisons with 16PF and OPQ (Dulewicz, 1995), the Big 5 (Lindgren, 1997) and Honey and Mumford's, Learning Style Questionnaire (Jackson, 2002) have produced only ambiguous support for the construct validity of BTRSPI and Belbin's underlying model (Anderson and Sleap, 2004). 
Table 1: Belbin's Role Characteristics

\begin{tabular}{|l|l|}
\hline Plant (PL) & Creative, imaginative, unorthodox. Solves difficult problems \\
\hline $\begin{array}{l}\text { Resource Investigator } \\
\text { (RI) }\end{array}$ & $\begin{array}{l}\text { Extrovert, enthusiastic, communicative. Explores } \\
\text { opportunities. Develops contacts. }\end{array}$ \\
\hline Co-ordinator (CO) & $\begin{array}{l}\text { Mature, confident, a good chairperson. Clarifies goals, } \\
\text { promotes decision-making, delegates well. }\end{array}$ \\
\hline Shaper (SH) & $\begin{array}{l}\text { Challenging, dynamic, thrives on pressure. The drive and } \\
\text { courage to overcome obstacles. }\end{array}$ \\
\hline Monitor Evaluator (ME) & $\begin{array}{l}\text { Sober, strategic and discerning. Sees all options. Judges } \\
\text { accurately. }\end{array}$ \\
\hline Team Worker (TW) & $\begin{array}{l}\text { Co-operative, mild, perceptive and diplomatic. Listens, } \\
\text { builds, averts friction. }\end{array}$ \\
\hline Implementer (IMP) & $\begin{array}{l}\text { Disciplined, reliable, conservative and efficient. Turns ideas } \\
\text { into practical actions. }\end{array}$ \\
\hline $\begin{array}{l}\text { Completer-Finisher } \\
\text { (CF) }\end{array}$ & $\begin{array}{l}\text { Painstaking, conscientious, anxious. Searches out errors } \\
\text { and omissions. Delivers on time. }\end{array}$ \\
\hline Specialist (SP) & $\begin{array}{l}\text { Single-minded, self-starting, dedicated. Provides knowledge } \\
\text { and skills in rare supply. }\end{array}$ \\
\hline
\end{tabular}

Source: Belbin Associates, 2004 e-Interplace IV material

Nevertheless, Belbin's ideas have been widely used by many UK organisations and management consultancies in both training and team development (Prichard and Stanton, 1999). The continuing research in Belbin's work is testimony to its influence in the study of team performance. Sustaining this has been the evidential support in the literature for the link between team role balance and team performance (Senior, 1997). Watkins and Gibson-Sweet (1997) established the link between role balance and successful project teams and Fisher et al. (1998) showed that dividing team roles into either 'task' or 'relationship' orientation could be used as a basis to predict team harmony and productivity. This study aims to contribute to the on-going research into Belbin's team roles.

\section{Team Role Balance and Team Development}

Belbin (1993) maintains that high performing teams need to have all nine roles, defined in Table 1, represented in the team. According to Belbin the degree of 'balance' in a team depends on the extent all nine roles are represented 'naturally'. Roles are identified as 'natural' in individuals who score 70 or above in a particular role in the SPI. A team member could have more than one 'natural' role. A 'secondary' role is one where an individual scores between 30 and 69 in that role. Senior (1997) believes that, while most team role theorists agree on the link between team diversity and team performance, the measurement of Belbin's team 'balance' is contentious. In an attempt to quantify 'balance' Partington and Harris (1999) formulated Team Balance Indices calculated from the aggregate score of team members spread across all roles. They defined the degree of team balance, firstly, by the deviation from an ideal index (i.e. the maximum score per team role that could be achieved with a given number of team 
members), secondly, where at least one person scored high or very high in as many as possible of the team roles and, thirdly, where only one person scored high or very high in as many as possible of the team roles. The result of the use of these indices was a strong negative correlation $(p<0.01)$ between the Co-ordinator $(C O)$ Role and team performance. The researchers attributed this to the negative effects that COs have on teams. The presence of a strong $\mathrm{CO}$ led to dependency and the lack of preparation by others and COs tended not to contribute creatively in the team's operational processes.

The performance of teams has also been attributed to the level of team development within the group. Researchers have hypothesised that teams develop in a linear and progressive way. Notably one of the most well known team development model is Tuckman's (1965) four-stage (Forming - Storming - Norming - Performing) model. A fifth stage (Adjourning) was later added in Tuckman and Jensen (1977) and Maples (1988). A fuller discussion on team development literature and research can be found in Smith (2001). Building on the team development research, McFadzean (2002) described a five-level model of team development associated with group performance in problem solving and decision-making. Team development was measured according to their focus or 'attention' to task (level one), the meeting process (level two), team structure (level three), team dynamics (level four) and team trust (level five). This model suggests that differing team performances can be associated with differences in team development. While this does not tell the direction of the causal relationship, it is interesting to see if team performance is indicative of differences in team processes, structure or activities associated with the varying stages of team development. The team development models developed by Tuckman and Jensen (1977) and McFadzean (2002) in relation to team performance are explored in this study.

\section{Research Aim}

The aim of this paper is to build on the empirical research on Belbin's team roles. It follows from the team roles-team performance line of inquiry. The predominance of each team role is quantified by aggregating the individual role scores of team members. It is then possible to examine relationships between team roles 'tendencies' and team performance. In pursuing the team effectiveness line of inquiry this research takes cognizance that teams evolve over time and there is no reason to believe that all teams are at the same stage of development at the time their performances are being measured. The research aims are distilled into seeking answers to two questions. Firstly, is there a relationship between the number and types of roles represented in a team and the team's overall performance? And, secondly, is there an association between team performance (and the roles represented therein) and its development stage? 


\section{Method}

\section{Sample}

A sample of 342 out of a cohort of 851 management students from Victoria University of Wellington participated in the survey. The ethnic composition of students was $48.8 \%$ European, 37.0\% Asian, 14.2\% New Zealand Maori or Pacific Islanders. The gender distribution was $48 \%$ female and $52 \%$ male. These students were organised into 33 teams that participated in a management simulation.

\section{Management simulation}

Each team operated as a management group planning the production of custom-made paper bags (Appendix B) that were sold to customers, acted out by trained role players. The teams were given a limited budget and had to perform the following functions: plan the purchase of supplies from a supplier (a trained role player), hire workers (role played by other students) and negotiate a loan, where necessary, from a banker (a trained role player). The timing of the simulation was fixed for each group and their performance was measured by the profit the teams made by the end of the week-long exercise. The team's performance formed a percentage of their management course marks. As an assessed part of a course procedures were put in place to ensure consistency and impartiality in the conduct of the simulation.

\section{Questionnaire}

The Belbin Team Role Self-Perception Inventory was used in this research. There were seven headings and ten behavioural statements under each heading (Appendix A). Respondents were asked to indicate their individual preferences by distributing ten points amongst these statements allocating more points to statement that reflected more strongly how they felt. They were asked to avoid the extremes of allocating all ten points to one statement or one point to each of the ten statements in a section. Each statement was associated with a particular team role and the number of times a team role statement was selected and the points allocated to it determined the respondent's team role preference. The respondents were unaware of this.

\section{Data collection and aggregation}

Participating members were assigned to their teams randomly and had been working as groups on various assessed tasks eight weeks prior to the start of the management simulation. During this period the questionnaire was administered and data collected on the number of times a team role statement was selected as well as the scores allocated to each selected statement. No information was given to the team members on their role preferences prior to the completion of the simulation. 
Belbin's (1993) classification of individuals into their 'natural' and 'secondary' roles applies to relatively small teams of up to six persons. A study of larger teams, as in this research (average team size $>10$ members), requires an analysis of the collective characteristics of team members (i.e. the number and intensity of characteristics individuals added to the team pool) as a possible determinant of team performance. This was done by scoring individuals on their team role characteristics and aggregating the scores within a team. The number of roles in which teams achieved an above average score was also recorded. The higher the number of roles the more 'balanced' the teams were. The team's performance was measured in the profit they secured by the end of the simulation. Teams were ranked into four performance categories - low, low average, high average and high. This categorisation would facilitate analysis by equalising the effects of minor variations in the profit figures.

\section{Focus groups}

All teams were required to attend focus groups after the simulation. Trained facilitators captured the salient discussion points on a set format recording responses in behavioural terms to questions such as: What went well and worked? What particular behaviours helped? These were recorded in the positive column (see Tables 3-6). Teams were also asked to respond to questions such as: What did not go well? What difficulties did you face? What behaviours hindered progress? These were recorded in the negative column (see Table 3-6). The focus groups provided qualitative data for this study.

\section{Analysis and Results}

Is there a relationship between the team roles represented in a team and its performance? The correlation analysis of team performance and team roles revealed significant positive relationships in the teams' performance ranking and their average role scores in PL, CO and TW. The results are in Table 2.

Table 2: Correlation between average team role scores and team performance ranking

\begin{tabular}{|l|c|c|}
\hline Belbin's Team Roles & Spearman's rho & $\begin{array}{c}\text { Significance } \\
{ }^{*} p<.05\end{array}$ \\
\hline PL: Plant & .373 & $.033^{*}$ \\
\hline RI: Resource Investigator & .293 & .098 \\
\hline CO: Co-ordinator & .419 & $.015^{*}$ \\
\hline SH: Shaper & .089 & .625 \\
\hline ME: Monitor Evaluator & .174 & .332 \\
\hline TW: Team Worker & .360 & $.040^{*}$ \\
\hline IMP: Implementer & .025 & .892 \\
\hline CF: Completer-Finisher & .238 & .182 \\
\hline SP: Specialist & .010 & .955 \\
\hline
\end{tabular}


However, this result does not indicate whether there is a relationship between team 'balance' and team performance. To determine this, the number of roles teams scored above the average was compared with their performance ranking. The correlation analysis showed a one-tailed non-statistically significant relationship (rho $=.258, p=$ .073) between the number of roles represented in a team (its balance) and its performance ranking. This result should be interpreted with caution given the small sample of 33 teams coupled with $p<.10$ result. No conclusion can be drawn as to whether more balanced teams would be advantaged or disadvantaged in their performance.

The second research question concerns the different stages of development teams go through and whether team role requirements remain the same throughout. In a facilitated focus group after the simulation, team members were asked to describe behaviours that assisted or hindered their group's performance during the planning and operating phases of the management simulation. The 33 teams had been classified into four categories of team performance - High (ranking 1-8), High-average (ranking 9-16), Low-average (ranking 17-24) and Low (ranking 25-33). The data from the focus groups were then extracted, collated and summarised into perceived events or behaviours that positively or negatively affected team performance.

In the High performing teams, members reported enthusiasm in taking on management roles that were defined by a leader (see Table 3 ). They managed their time effectively working within their own remit. As a group, they worked well under pressure. However, these teams were hindered by argument amongst themselves, which could have precipitated from them being delegated work that was seen as inappropriate. They also reported insufficient time being allocated to planning the production process. This was compounded by the perception of workers being inefficient and needing extra guidance and control.

Table 3: Observations of High Performing Teams

\begin{tabular}{|c|c|}
\hline \multicolumn{2}{|c|}{ Events or behaviours affecting team performance } \\
\hline Positive & Negative \\
\hline $\begin{array}{l}\text { - Team members take on management roles } \\
\text { enthusiastically } \\
\text { - A committed core group of managers emerges } \\
\text { - Good communication between team members } \\
\text { - } \text { Control over team activities } \\
\text { from the leader } \\
\text { - Managers' roles defined by the leader } \\
\text { - Managers were responsible over their own areas } \\
\text { - Team members work well under pressure } \\
\text { - The least time was spent on the least important } \\
\text { matters }\end{array}$ & $\begin{array}{l}\text { - } \begin{array}{l}\text { Argument amongst } \\
\text { managers }\end{array} \\
\text { - Team members rushed } \\
\text { through the planning } \\
\text { phase } \\
\text { - } \quad \text { Leader faced difficulty in } \\
\text { delegating } \\
\text { - Workers were seen as } \\
\text { inefficient (slow and lazy) }\end{array}$ \\
\hline
\end{tabular}


The High-average performing teams appeared, in Table 4, to be people-centred. There was an emphasis on securing consensus, morale building and effective training. An outcome of this approach was more disagreements with the leader and more time required for decisions. The decisions that were eventually made were seen as being forced upon team members by their leader. The leadership of these groups were characterised as being risk-averse and lacking in direction.

Table 4: Observations of High-Average Performing Teams

\begin{tabular}{|c|c|}
\hline \multicolumn{2}{|c|}{ Events or behaviours affecting team performance } \\
\hline Positive & Negative \\
\hline $\begin{array}{l}\text { - Leader influenced others to reach goals } \\
\text { - Reassurances were provided to team } \\
\text { members that they were on the right track } \\
\text { - Team members were encouraged to speak in } \\
\text { meetings } \\
\text { - How other teams performed were observed in } \\
\text { order to learn } \\
\text { - Attempts were made to increase group morale } \\
\text { - Activities were monitored to ensure } \\
\text { - Compliance with plans } \\
\text { - } \text { others explanations were provided to convince } \\
\text { - Natural leader stood in when the appointed } \\
\text { leader was absent } \\
\text { - Training of workers was done effectively }\end{array}$ & 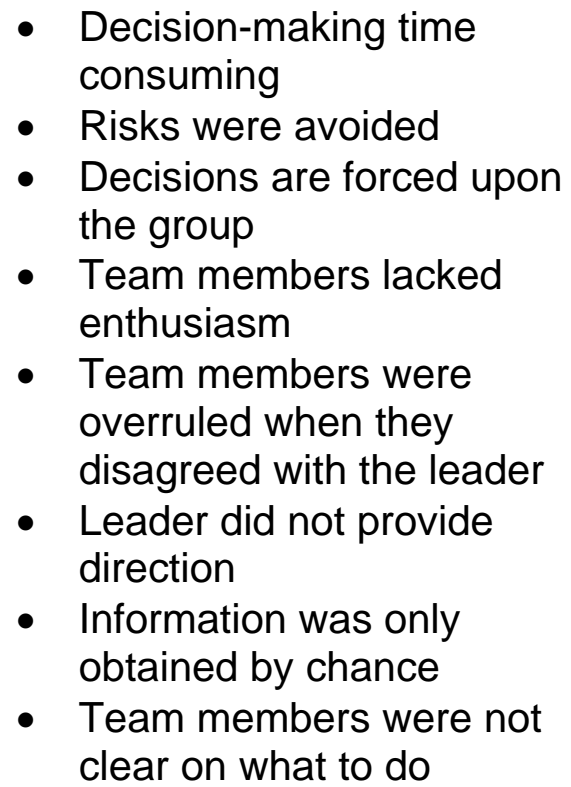 \\
\hline
\end{tabular}

The recorded observations in Low-average performing teams, in Table 5, indicated consultation in determining managerial roles. In some cases members were selected to perform roles based on their work experience. Plans set in place were followed closely with the view of optimising the used of resources and, where possible, learning from the experience of other teams. The poor performance was attributed to reluctance to take on the leadership role, a lack of commitment of managers to their jobs, a lack of communication amongst members and insufficient time and resources to get the job done.

The Low performing teams appeared to have members who took the initiative in assuming leadership roles as well as in securing crucial information from outside the group (see Table 6). There was evidence that these teams initiated 'training' of team members and had done detailed planning of activities. However, team members seemed to lack self-confidence as well as confidence in their leaders.

Were the team role requirements different for teams at the different stages of development as indicated by the behaviours in their performance categories? The average team role scores in each team were compared amongst the four performance 
categories. Each category was compared with the other three. The results from six comparisons revealed statistically significant differences in two comparisons. Table 7 shows the comparisons of High and High Average performing teams. The High performing teams had a significantly higher SP score than the High Average performing teams.

Table 5: Observations of Low-Average Performing Teams

\begin{tabular}{|l|l|}
\hline \multicolumn{2}{|c|}{ Events or behaviours affecting team performance } \\
\hline \multicolumn{1}{|c|}{ Positive } & \multicolumn{1}{c|}{ Negative } \\
\hline $\begin{array}{l}\text { Team members were } \\
\text { consulted on their role } \\
\text { preferences }\end{array}$ & - $\begin{array}{l}\text { Appointed leader was reluctant to take on the } \\
\text { leadership role }\end{array}$ \\
- $\begin{array}{l}\text { Managers were chosen } \\
\text { based on their past } \\
\text { experiences }\end{array}$ & There were arguments over managerial roles \\
members wanted
\end{tabular}

Table 6: Observations of Low Performing Teams

\begin{tabular}{|c|c|}
\hline \multicolumn{2}{|c|}{ Events or behaviours affecting team performance } \\
\hline Positive & Negative \\
\hline $\begin{array}{l}\text { - Leader volunteered as } \\
\text { well as appointed the } \\
\text { other managers } \\
\text { - Team was divided into } \\
\text { functional groups } \\
\text { - Team members } \\
\text { looked to the leader } \\
\text { for guidance } \\
\text { - Leader attempted to } \\
\text { teach team members } \\
\text { on production process } \\
\text { - Team members on }\end{array}$ & $\begin{array}{l}\text { - Person asked to be leader refuses } \\
\text { - } \quad \text { Team members were unenthusiastic about their role } \\
\text { - } \text { disagreements with the leader were summarily } \\
\text { - Members lost confidence in leader and talked of a } \\
\text { - } \text { coup d'etat } \\
\text { - } \text { It was difficult to fix time to meet } \\
\text { - Many members did not attend key meetings } \\
\text { - Plans were changed at the last minute } \\
\text { - } \text { Workers were not as efficient as they could be } \\
\text { - Controlling workers was hard when managers were }\end{array}$ \\
\hline
\end{tabular}


their own initiative, clarified instructions on the simulation

- Plans were made to the smallest detail

\section{stressed}

- The was poor support for the leader

- Team members confused about their roles

Table 7: Difference in team role scores between high and high-average performing teams

\begin{tabular}{|c|c|c|c|c|c|c|}
\hline \multirow{2}{*}{$\begin{array}{l}\text { Belbin Team } \\
\text { Roles }\end{array}$} & \multicolumn{2}{|c|}{$\operatorname{High}(\mathrm{N}=8)$} & \multicolumn{2}{|c|}{ High Ave $(\mathrm{N}=8)$} & \multirow[b]{2}{*}{$\begin{array}{l}t \text {-value } \\
(\mathrm{df}=14)\end{array}$} & \multirow{2}{*}{$\begin{array}{l}\text { t-test } \\
\text { significance } \\
{ }^{\star} \mathrm{p}<.05\end{array}$} \\
\hline & Mean & Std Dev & Mean & Std Dev & & \\
\hline PL: Plant & 3.241 & 651 & 3.271 & 640 & -.093 & .927 \\
\hline $\begin{array}{l}\text { RI: Resource } \\
\text { Investigator }\end{array}$ & 4.012 & .639 & 4.035 & .820 & -.060 & .953 \\
\hline CO: Coordinator & 3.432 & 368 & 3.670 & .805 & -.758 & .461 \\
\hline SH: Shaper & 4.125 & 1.100 & 3.788 & .559 & .773 & .453 \\
\hline $\begin{array}{l}\text { ME: Monitor } \\
\text { Evaluator }\end{array}$ & 4.036 & .781 & 3.917 & .470 & .370 & .717 \\
\hline $\begin{array}{l}\text { TW: Team } \\
\text { worker }\end{array}$ & 3.997 & .871 & 4.145 & .692 & -.373 & .713 \\
\hline $\begin{array}{l}\text { IMP: } \\
\text { Implementer }\end{array}$ & 4.312 & .697 & 4.164 & .550 & 471 & 645 \\
\hline $\begin{array}{l}\text { CF: Completer- } \\
\text { finisher }\end{array}$ & 3.940 & .922 & 3.864 & .708 & 184 & .856 \\
\hline SP: Specialist & 4.596 & .787 & 3.925 & .375 & 2.175 & $.047^{*}$ \\
\hline
\end{tabular}

The comparison between High and Low performing teams, in Table 8, also revealed a significant result. The Low performing teams had a significantly higher $\mathrm{CO}$ score than the High performing teams.

Table 8: Difference in team role scores between high and low performing teams

\begin{tabular}{|l|l|l|l|l|l|l|}
\hline \multirow{2}{*}{$\begin{array}{l}\text { Belbin Team } \\
\text { Roles }\end{array}$} & \multicolumn{3}{l|}{ High (N=8) } & \multicolumn{2}{l|}{ Low $(\mathrm{N}=9)$} & $\begin{array}{l}\text { t-test } \\
\text { significance } \\
\text { tp }<.05\end{array}$ \\
\cline { 2 - 7 } & Mean & Std Dev & Mean & Std Dev & $\begin{array}{l}\text { t-value } \\
(\mathrm{df}=15)\end{array}$ \\
\hline PL: Plant & 3.241 & .651 & 3.737 & .810 & -1.381 & .188 \\
\hline $\begin{array}{l}\text { RI: Resource } \\
\text { Investigator }\end{array}$ & 4.012 & .639 & 4.265 & .542 & -.881 & .392 \\
\hline CO: Coordinator & 3.432 & .368 & 4.114 & .639 & -2.647 & $.018^{*}$ \\
\hline SH: Shaper & 4.125 & 1.100 & 3.534 & .660 & 1.361 & .194 \\
\hline $\begin{array}{l}\text { ME: Monitor } \\
\text { Evaluator }\end{array}$ & 4.036 & .781 & 4.228 & 1.109 & -.408 & .689 \\
\hline TW: Team worker & 3.997 & .871 & 4.392 & .646 & -1.068 & .302 \\
\hline IMP: Implementer & 4.312 & .697 & 4.301 & .877 & .027 & .978 \\
\hline
\end{tabular}




\begin{tabular}{|l|l|l|l|l|l|l|}
\hline $\begin{array}{l}\text { CF: Completer- } \\
\text { finisher }\end{array}$ & 3.940 & .922 & 4.157 & .893 & -.493 & .629 \\
\hline SP: Specialist & 4.60 & .787 & 4.451 & .858 & .361 & .723 \\
\hline
\end{tabular}

\section{Discussion}

The quantitative analysis in this study was carried out using aggregate data to measure Belbin's team roles. While no attempt will be made to generalise the findings in this study to the roles individuals play in contributing to team performance, the results provided insight into the team performances where there appeared to be a group propensity towards behaviours characterised by established roles.

There were significant correlations between PL, CO and TW scores and team performance. This suggests that teams that were more creative, had clear goals, coordinated activities and members who were generally more co-operative achieved better results. However, this also means that any one of the characteristics represented by the $\mathrm{PL}, \mathrm{CO}$ and TW roles could be associated with making the difference in team performance.

There was no significant relationship between the more 'balanced' teams measured by the number of roles represented, and their performance in the management simulation. The classification of the teams into four performance categories moved the analysis to the next stage by providing the basis for comparisons between teams at varying stages of development.

High performing teams were characterised by trust, good communication, high commitment and good time management amongst team members. This appears to support McFadzean (2002) assertion that better developed high performing teams reported trust between their leaders and team members ('attention to team trust'- level five development). There was a high level of commitment amongst team members through participation ('attention to team dynamics' - level four development). High Average team members in this research appeared to require more reassurances, encouragement and closer supervision. The comparison of these two groups revealed a significant difference in the SP role. This suggests that more developed teams which are already doing well could do better by having the appropriate Specialist knowledge.

Low performing teams were characterised by 'forming' stage behaviours such as mistrust, a lack of commitment, and poor leadership. The analysis of data showed that these teams were significantly higher in their CO role. This is interesting because it is contrary to the significant $(p<.015)$ positive correlation that had been established between teams $\mathrm{CO}$ scores and the team performance ranking. It also provides empirical evidence suggesting that teams require different role set at different stages of development. It would appear more conceivable then that $\mathrm{CO}$ role behaviours such as goal clarification, delegation and coordination for teams at a 'lower' stage of development would be inappropriate to increase performance. This observation supports 
Partington's and Harris' (1999) assertion that the predominance of COs led to dependency and inertia from others who would have otherwise come forward and contribute to their team's performance.

\section{Conclusion}

Team role characteristics defined by creativity ( $\mathrm{PL}$ role), good co-ordination (CO role) and good co-operation (TW role) when measured collectively are correlated with team performance. There does not appear to be a statistically significant relationship between team 'balance' and team performance. However, there are differences in behaviours of team members when classified according to team performance. These can be associated with the stages of team development. The high performing teams are associated with the 'team trust' and 'team dynamics' stages of development. Further research is required to establish definitive behaviours characterising the team development stages.

The examination of the aggregate scores in relation to the level of team performance reveals that amongst more developed teams higher SP scores, which can be translated into having more relevant expertise in completing a task, are associated with better performance. While the $\mathrm{CO}$ characteristics are generally positively associated with performance, this can impede performance of teams that have not reached a certain stage of development. More research is therefore required into team role characteristics and the stages of team development, and the relationship of these two with regards to team performance.

\section{References}

Anderson, N. and Sleap, S. (2004), 'An evaluation of gender differences on the Belbin Team Role Self-Perception Inventory', Journal of Occupational and Organizational Psychology, 77, 3, 429-437

Bales, R. F. (1950), 'A set of categories for the analysis of small group interaction', American Sociological Review, 15, 257-63

Belbin Associates (2004), Interplace IV Human Resource Management System User's Manual, Cambridge

Belbin, R. M. (1981) Management Teams: Why They Succeed or Fail, ButterworthHeinemann, Oxford

Belbin, R. M. (1993) Team Roles at Work, Butterworth-Heinemann, Oxford

Benne, K. D. and Sheats, P (1948), 'Functional roles of group members', Journal of Social Issues, 4, 41-9

Cohen, S. G. and Ledford, G. E. Jr. (1994), 'The effectiveness of self-managing teams: A quasi-experiment', Human Relations, 47, 13-43 
Davis, J., Millburn, P., Murphy, T. and Woodhouse, M. (1992), Successful Team Building: How to Create Teams that Really Work, Kogan Page, London

Deihl, M. and Stroebe, W. (1987), 'Productivity loss in brainstorming groups: towards the solution of a riddle', Journal of Personality and Social Psychology, 53, 3, 497-509

Dulewicz, V. (1995), 'A validation of Belbin's team role from 16PF and OPQ using bosses' ratings of competence', Journal of Occupational and Organizational Psychology, $68,81-99$

Evenden, R. and Anderson, G. (1992), Making the Most of People, Addison-Wesley, Cambridge, MA

Fisher, S. G., Hunter, T. A. and Macrosson, W. D. K. (1998), The structure of Belbin's team roles', Journal of Occupational and Organizational Psychology, 71, 3, 283-288

Fleming, Q.W. and Koppleman, J.M. (1997), 'Integrated project development teams: another fad ... or a permanent change?' Project Management Journal, 28, 1, 4-11.

Furnham, A., Steele, H. and Pendleton, D. (1993), 'A psychometric assessment of the Belbin team role self-perception inventory', Journal of Occupational and Organizational Psychology, 66, 245-257.

Gersick, C. J. G. (1988), 'Time and transition in work teams: toward a new model of group development', Academy of Management Journal, 31, 1, 9-41

Jackson, C. J. (2002), 'Predicting team performance from a learning process model', Journal of Managerial Psychology, 17, 1, 6-13

Katzenbach, J. R. (1998), 'Teams at the Top: Unleashing the Potential of Both Teams and Individual Leaders', Harvard Business School Press, Boston, MA

Kozlowski, S.W.J. and Klein K.J. (2000), 'A multilevel approach to theory and research in organizations: Contextual, temporal, and emergent processes'. In Multilevel theory, research, and methods in organizations: Foundations, extensions, and new directions, Klein K.J. and Kozlowski, S.W.J. (Eds.), Jossey-Bass, San Francisco

Lindgren, R. (1997), R Meredith Belbin's Team Roles Viewed from the Perspective of the Big 5: A Content Validation, University of Oslo, Oslo

Maples, M. F. (1988), ‘Group development: Extending Tuckman's theory', Journal for Specialists in Group Work, 13, 17-23

Margerison, C. and McCann, D. (1990), Team Management, W. H. Allan, London 
McFadzean, E. (2002), 'Developing and supporting creative problem-solving teams: Part 1 - a conceptual model', Management Decision, 40, 5/6, 463-476

Parker, G. M. (1990), Team Players and Teamwork: The Competitive Business Strategy, Jossey-Bass, Oxford

Partington, D. and Harris, H. (1999), 'Team balance and team performance: an empirical study', The Journal of Management Development, 18, 8, 694-701

Pervin, L. (1989), Personality: Theory and Research, Wiley ( ${ }^{\text {th }}$ Ed.), New York

Prichard, J. S. and Stanton, N. A. (1999), 'Testing Belbin's team role theory of effective groups', The Journal of Management Development, 18, 8, 652-660

Senior, B. (1997), 'Team roles and team performance: Is there 'really' a link?', Journal of Occupational and Organizational Psychology, 70, 3, 241-258

Smith, G. (2001), 'Group development: A review of the literature and a commentary on future research directions', Group Facilitation, St. Paul, Spring, 3, 14-45

Spencer, J. and Pruss, A. (1992), Managing your team, Piatkus, London

Tuckman, B. W. (1965), "Developmental sequence in small groups', Psychological Bulletin, 63, 348-399

Tuckman, B. W. and Jensen, M. C. (1977), 'Stages of small-group development revisited', Group and Organisation Studies, 2(4), 419-170

Watkins, B. and Gibson-Sweet, M. (1997), 'Sailing with Belbin', Education \& Training, $39,2 / 3,105-110$

West, M. A. and Markiewicz, L. (2004), 'Building team-based working: A practical guide to organizational transformation', Oxford, Blackwell.

Woodcock, M. (1989), Team Development Manual, Gower, Aldershot 


\section{Belbin's Team Role Self-Perception Inventory}

Appendix A

Section I: What I believe I can contribute to a Team
10 I think I can quickly see and take advantage of new opportunities.

11 My comments on both general and specific points are well received.

12 I can work well with a very wide range of people.

13 Producing ideas is one of my natural assets.

14 My ability rests in being able to draw people out whenever I

detect they have something of value to contribute to group objectives

15 I can be relied upon to finish any task I undertake.

$16 \mathrm{My}$ technical knowledge and experience is usually my

major asset

$\mathbf{1 7}$ I am prepared to be blunt and outspoken in the cause of making the right things happen.

$\mathbf{1 8}$ I can usually tell whether a plan or idea will fit a particular situation

19 I can offer a reasoned and unbiased case for alternative courses of action.

Section II: If I have a possible shortcoming in team work, it could be that.

$20 \mathrm{I} \mathrm{am}$ not at ease unless meetings are well structured and controlled and generally well conducted.

21 I am inclined to be too generous towards others who have a valid viewpoint that has not been given a proper airing.

22 I am reluctant to contribute unless the subject deals with an area I know well.

23 I have a tendency to talk a lot once the group gets on to a new topic.

$24 \mathrm{I}$ am inclined to undervalue the importance of my own contributions.

25 My objective outlook makes it difficult for me to join in readily and enthusiastically with colleagues.

$26 \mathrm{I}$ am sometimes seen as forceful and authoritarian when dealing with important issues.

27 I find it difficult to lead from the front, perhaps because I am over responsive to group atmosphere.

$28 \mathrm{I} \mathrm{am}$ apt to get too caught up in ideas that occur to me and so lose track of what is happening.

29 I am reluctant to express my opinions on proposals or plans that are incomplete or insufficiently detailed.

Section III: When involved in a project with other people.. 30 I have an aptitude for influencing people without pressurizing them.

31 I am generally effective in preventing careless mistakes or omissions from spoiling the success of an operation.

32 I like to press for action to make sure that the meeting does not waste time or lose sight of the main objective.

33 I can be counted on to contribute something original.

$34 \mathrm{I}$ am always ready to back a good suggestion in the common interest.

35 One can be sure I will just be my natural self.

36 I am quick to see the possibilities in new ideas and developments.

37 I try to maintain my sense of professionalism.

38 I believe my capacity for judgement can help to bring about the right decisions.

39 I can be relied on to bring an organised approach to the demands of the job.

Section IV: My characteristic approach to group work is

that..

$\mathbf{4 0}$ I maintain a quiet interest in getting to know colleagues better.

$\mathbf{4 1}$ I contribute where I know what I am talking about.

42 I am comfortable challenging the view of others or holding a minority view myself.
43 I can usually find a line of argument to refute unsound propositions.

44 I think I have a talent for making things work once a plan has to be put into operation.

45 I prefer to avoid the obvious and to open up lines that have not been explored.

46 I bring a touch of perfectionism to any job I undertake.

47 I like to be the one to make contacts outside the group or the firm.

48 I enjoy the social side of working relationships.

49 While I am interested in hearing all views I have no hesitation in making up my mind once a decision has to be made.

Section V: I gain satisfaction in a job because..

$50 \mathrm{I}$ enjoy analysing situations and weighing up all the possible choices.

$\mathbf{5 1}$ I am interested in finding practical solutions to problems. 52 I like to feel I am fostering good working relationships.

53 I can have a strong influence on decisions.

54 I have a chance of meeting new people with different ideas.

$\mathbf{5 5}$ I can get people to agree on priorities and objectives.

56 I feel in my element where I can give a task my full attention.

$\mathbf{5 7}$ I can find an opportunity to stretch my imagination.

58 I feel that I am using my special qualifications and training to advantage.

59 I usually find a job gives me the chance to express myself.

Section VI: If I am suddenly given a difficult task with

limited time and unfamiliar people..

60 I usually succeed in spite of the circumstances.

61 I like to read up as much as I conveniently can on the subject.

62 I would feel like devising a solution of my own and then trying to sell it to the group.

63 I would be ready to work with the person who showed the most positive approach.

64 I would find some way of reducing the size of the task by establishing how different individuals can best contribute. 65 My natural sense of urgency would help to ensure that we did not fall behind schedule.

66 I believe I would keep cool and maintain my capacity to think straight.

67 In spite of conflicting pressures I would press ahead with whatever needed to be done.

68 I would take the lead if the group was making no progress. 69 I would open discussions with a view to stimulating new thoughts and getting something moving.

Section VII: With reference to the problems I experience when working within groups..

$70 \mathrm{I}$ am apt to overreact when people hold up progress. 71 Some people criticize me for being too analytical.

72 My desire to check that we get the important details right is not always welcome.

$\mathbf{7 3}$ I tend to show boredom unless I am actively engaged with stimulating people.

74 I find it difficult to get started unless the goals are clear.

$75 \mathrm{I}$ am sometimes poor at putting across complex points that occur to me.

76 I am conscious of demanding from others the things I cannot do myself.

77 I find others do not give me enough opportunity to say all I want to say.

$78 \mathrm{I}$ am inclined to feel I am wasting my time and would do better on my own.

79 I hesitate to express my personal views in front of difficult or powerful people. 


\section{Management simulation - product specifications}

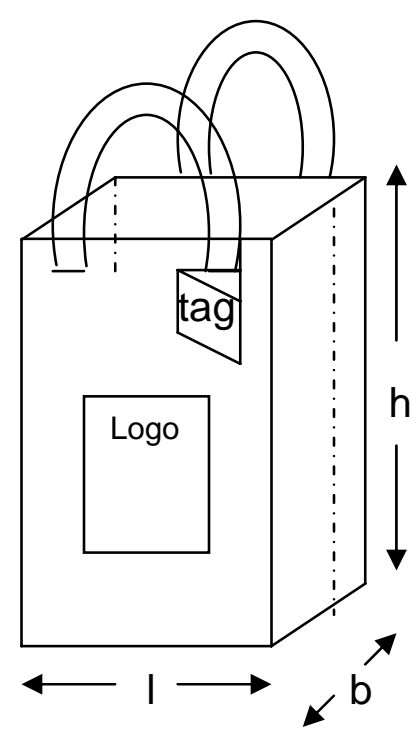

High Quality Pak

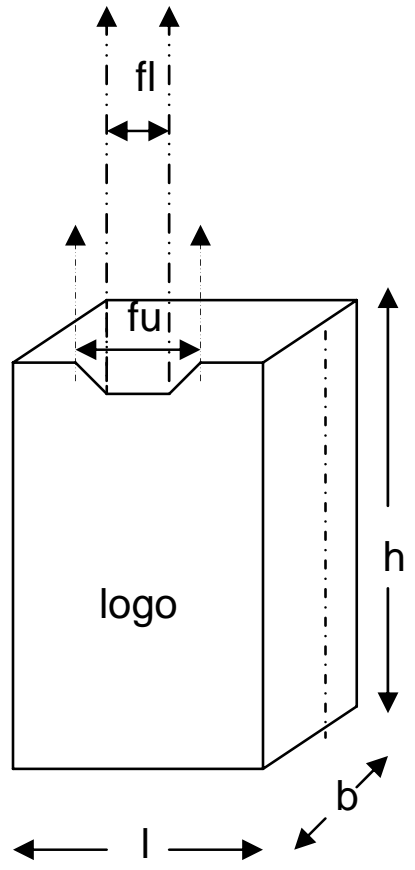

Regular Pak

Dimensions of Regular Pak and Higher Quality Pak

Large size $-\mathrm{I}=27 \mathrm{~cm}$

$$
\begin{aligned}
& \mathrm{b}=15 \mathrm{~cm} \\
& \mathrm{~h}=33 \mathrm{~cm}
\end{aligned}
$$

Small size $-\mathrm{I}=13 \mathrm{~cm}$

$$
\begin{aligned}
& \mathrm{b}=8 \mathrm{~cm} \\
& \mathrm{~h}=24 \mathrm{~cm}
\end{aligned}
$$

Width of handle $=3 \mathrm{~cm}$ Length of handle $=27 \mathrm{~cm}$

$$
\begin{aligned}
& \mathrm{f}_{\mathrm{u}}=7 \mathrm{~cm} \\
& \mathrm{f}_{\mathrm{l}}=4 \mathrm{~cm}
\end{aligned}
$$

